\title{
Angiogenesis and Fibroblast Growth Factors (FGFs) in a Three-Dimensional Collagen Gel Culture
}

\author{
By \\ Takashi NAgATORO ${ }^{1}$, Keiko FUJITA ${ }^{1}$, Eiko MURATA ${ }^{1}$ and Masumi AKITA $^{2}$ \\ ${ }^{1}$ Dept. of Anatomy, ${ }^{2}$ Division of Morphological Science, Biomedical Research Center, Saitama Medical School, \\ Moroyama, Iruma-gun, Saitama 350-0495, Japan
}

- Received for Publication, February 7, $2003-$

Key Words: Angiogenesis, FGF-2, FGF-9, Collagen Gel Culture, RT-PCR

\begin{abstract}
Summary: Small pieces of mouse aorta were cultured in collagen gels, and the formation of capillary-like tubes from the aortic explant was observed under phase-contrast and transmission electron microscopes. Migration of fibroblastic cells from the aortic explant occurred in 2 days. After about 10 days of culture, capillary-like tubes from the aortic explant were formed in the collagen gels. An immunohistochemical study on the collagen gel culture revealed the expression of fibroblast growth factor 2 (FGF-2) near the aortic explant at the active initial stage, with random migration of fibroblastic cells expressing FGF-9. mRNA was isolated from these cultures, and reverse transcription-polymerase chain reaction (RT-PCR) of the cultures revealed the expressions of both FGF-2 and FGF-9. Based on our results, we propose that FGF-9 is also related to angiogenic events.
\end{abstract}

Angiogenesis, the development of vessels from preexisting vessels, is essential for a variety of physiologic processes, including organ development (Adams et al., 1999; Erlebacher et al., 1995), wound healing (Nissen et al., 1998), and reproduction (Tamura and Greenwald, 1987). Several techniques have been developed for in vitro studies on angiogenesis. In experiments from the early 1980's, researchers found that they could induce the formation of capillary-like tubes by embedding pure endothelial cells in collagen gel (Folkman and Haudenschild, 1980; Montesano et al., 1983). Later, researchers induced angiogenesis in tissues with the use of fibrin and collagen gels (Montesano et al., 1985), as well as matrigel, collagen, fibrin, and plasma clot (Nicosia and Ottinetti, 1990a). Among these various techniques, the culture of blood vessels in collagen gels has been reported to yield relatively steady results (Mori et al., 1988; Nicosia and Ottinetti, 1990b; Akita et al., 1997a, b).

A variety of growth factors are expressed at the site of angiogenesis. The fibroblast growth factors (FGFs) are a family of heparin-binding proteins involved in many biological processes in both developing and adult mammals, including cell prolifera- tion, differentiation, and angiogenesis (Cancilla et al., 2001). The actions of the FGFs, particularly the basic form (basic FGF $=$ FGF-2), have been described in a large number of cells (for a review see Bikfalvi et al., 1997). In this study, aortic explants from mice were cultured in collagen gels. Examination of these cultures by reverse transcriptionpolymerase chain reaction (RT-PCR) and immunohistochemistry revealed the expressions of both FGF-2 and FGF-9. FGF-2 is well known as an angiogenic factor. We propose that FGF-9 also relates to angiogenic events in the collagen gel culture.

\section{Materials and Methods}

\section{Collagen gel culture}

This culture technique has already been described by Akita et al. (1993, 1997a, b). Thoracic aortae were obtained from 1-month-old ICR male mice. After separating the tunica adventitia from the aorta under a stereoscopic microscope, the blood vessel specimens were cut into small pieces of $3-5 \mathrm{~mm}$ in length, placed at the bottom of a tissue culture plate (Falcon 35/3047), overlaid with an 
even layer of reconstituted collagen solution (0.3\% Cellmatrix type IA, Nitta Gelatin), and allowed to gel at $37^{\circ} \mathrm{C}$ for about $10 \mathrm{~min}$. After the gels had formed, they were overlaid with Ham's F-12 medium (Bioproducts) containing 10\% fetal bovine serum (FBS), 1\% non-essential amino acids, $2 \mathrm{mM}$ L-glutamine, 100 Units $/ \mathrm{ml}$ penicillin, and $100 \mathrm{mg} / \mathrm{ml}$ streptomycin (Bioproducts), and cultured for 2 weeks in an incubator $(95 \%$ air $/ 5 \%$ $\mathrm{CO}_{2}$ ). The culture medium was replaced halfway through the incubation, at 1 week.

\section{Electron microscopy}

The cultured materials were fixed in $0.1 \mathrm{M}$ phosphate buffer $(\mathrm{pH} 7.2)$ containing $2.5 \%$ glutaraldehyde for 1 hour, and fixed in $0.1 \mathrm{M}$ phosphate buffer $\left(\mathrm{pH}\right.$ 7.2) containing $1 \% \mathrm{OsO}_{4}$ for another hour. The specimens were then dehydrated with ethanol, embedded in epoxy resin, cut into ultrathin sections, and stained with uranyl acetate and lead citrate. The stained sections were observed under a transmission electron microscope (Hitachi H-7000).

\section{$R T-P C R$}

The following methods were used to isolate mRNA and prepare cDNA for the RT-PCR analysis. The expressions of nine FGF family genes (FGF-1, -2, -3, -4, -5, -6, -7, -8, -9) were analyzed. We adopted several conditions from the method developed by Ozawa et al. (1997), including the PCR primers, $\mathrm{pH}$ and $\mathrm{Mg}^{2+}$ concentration, annealing temperature, and number of cycles for amplification of FGF and GAPDH (as a control) cDNAs. 1. Grind cells migrating from the aortic explant into a mortar on liquid nitrogen. Add Lysis/Binding Buffer ( $\mu M A C S$ mRNA Isolation Kit; Daiichi Chemical).

2. Apply the sample on top of the Lysate Clear Column.

3. Add Oligo (dT) Micro Beads to the tissue.

4. Place a MACS Column Type $\mu$ in the magnetic field.

5. Apply tissue from Lysis/Binding Buffer.

6. Apply tissue lysate on top of the column matrix, and let the lysate pass through (magnetically labeled mRNA is retained in the column).

7. Rinse the column with Lysis/Binding Buffer to remove proteins and DNA.

8. Rinse the column with Wash Buffer to remove rRNA and DNA.

9. Apply pre-heated Elution Buffer for elution of the mRNA.

10. Perform the first-strand cDNA synthesis from the template RNA (Ready-To-Go; You-Prime FirstStrand Beads; Pharmacia).

11. RT-PCR.

Thermal cycling reaction using a DNA thermal cycler device (Takara PCR Thermal Cycler MP): The thermocycling program consisted of a $94^{\circ} \mathrm{C}$ hot start, followed by 35 cycles of $94^{\circ} \mathrm{C}$ for $1 \mathrm{~min}$, $55-70^{\circ} \mathrm{C}$ for $1 \mathrm{~min}$, and $72^{\circ} \mathrm{C}$ for $1 \mathrm{~min}$, followed by a final extension at $72^{\circ} \mathrm{C}$ for $5 \mathrm{~min}$. RT-PCR products electrophoresed through $1 \%$ agarose gels were visualized by ethidium bromide staining and UV transillumination.

\section{Immunohistochemistry}

Factor VIII-related antigen (von-Willebrandfactor): The gels were detached from the culture dish with a spatula, placed evenly on a glass slide, covered with a lens tissue and filter paper, and pressed for 1 min (Mori et al., 1988). After gently removing the papers, the gels were air-dried and used for immunostaining for factor VIII-related antigen. The dried gels were fixed with acetone for $5 \mathrm{~min}$. After pretreatment with normal serum, they were washed with phosphate-buffered saline (PBS), incubated with goat anti-human factor VIII-related antigen (Biomeda Corp., USA) for $60 \mathrm{~min}$, washed with PBS, reincubated with biotinylated goat IgG for $20 \mathrm{~min}$, washed and incubated with peroxidase avidin, and stained with AEC and $0.02 \% \mathrm{H}_{2} \mathrm{O}_{2}$ in PBS. Gels incubated with normal goat serum instead of anti-human factor VIII-related antigen antibody were used as control.

FGF-2 and FGF-9: The gels were detached from the culture dish with a spatula, fixed in $10 \%$ formalin for 1 hour, pretreated with normal serum, and washed with PBS. For immunocytochemistry, the gels were incubated for 5 min with $3 \%$ hydrogen peroxide to suppress endogenous peroxidase activity. Next, they were incubated overnight at $4{ }^{\circ} \mathrm{C}$ with the one of the following antibodies: antihuman FGF-2; 147, sc-79 (this antibody reacts with FGF-2 of mouse, rat and human origin; Santa Cruz Biotechnology) or anti-mouse FGF-9 (Antigenix America). After washing with PBS, the primary antibody was detected with streptavidin-biotin by the DAKO LSAB2 kit according to the manufacturer's instructions. The specimens were then treated by sequential 15 -minute incubations with the biotinylated link antibody and peroxidaselabeled streptavidin. The last stage of staining was a 5-minute incubation with the substrate-chromogen solution (AEC and $0.02 \% \mathrm{H}_{2} \mathrm{O}_{2}$ in PBS). Gels incubated with normal rabbit serum instead of antibodies were used as controls.

\section{Results}

\section{Light and electron microscopy}

Spindle-shaped cells began migrating from the aortic explant after 2 days of culture. Three to four 



Fig. 1. a. Phase-contrast micrograph of the migrating cells into the collagen gels. After 5 days in culture, cell migration occurred from the end of the aortic explant (asterisk). Capillary-like tubes are not formed at this time. $\times 100$

b. Electronmicrograph of the migrating cells into the upper layer of collagen gels. These cells exhibited fibroblastic characteristics in the morphology. $\times 5,500$

layers of what morphologically resembled fibroblastic cells were overlaid on the superficial and bottom layers of the collagen gels, and migrating cells were also seen in the middle layer. However, no tubular structure was visible at this time (Fig. 1a, b). The formation of capillary-like tubes first appeared after about 10 days of culture (Fig. 2a). Formations of capillary-like tubes consisting of 2-3 cells each were found in the collagen gels. Weibel-Palade bodies were observed in the cells (Fig. 2b).

\section{$R T-P C R$}

FGF-2 expression was observed at the active initial stage, with random migration of fibroblastic cells from the aortic explant, before the capillarylike tube formation. RT-PCR did not detect any FGF-9 expression at this time. Once the capillarylike tube formation was underway, expressions of both FGF-2 and FGF-9 were observed (Fig. 3, 4).

\section{Immunohistochemistry}

Capillary-like tubes were positive for the immunostaining of factor VIII-related antigen (Fig. 5). FGF-2 expression was observed in the fibroblastic cells migrating from the aortic explant at the active initial stage (Fig. 6a), but the expression grew indistinct with time. The capillary-like tubes were negative for the immunostainings of FGF-2 and FGF-9. The migrating fibroblastic cells also expressed FGF-9. After capillary-like tube formation, the FGF-9-positive cells were dominant (Fig. $6 b)$.

\section{Discussion}

To study the process of angiogenesis and test new agents with (anti)-angiogenic potential, suitable assays are essential (Deckers et al., 2001). The most commonly used in vivo assays are the corneal micropocket assay, the chorioallantoic membrane (CAM) assay, and the dorsal skin-fold assay (Fournier et al., 1981; Jakob et al., 1978; Kenyon et al., 1996). The corneal micropocket assay, an analysis conducted within an avascular environment, is often used to study the efficacy of angiogenic compounds. The efficacy of anti-angiogenic compounds in inhibiting growth factor inducedvascularization and spontaneous vascularization is usually studied in vascular environments such as the CAM assay or the dorsal skin-fold assay. These assays have proven useful and have dramatically advanced our knowledge of angiogenesis. However, they are also limited in several respects (for a detailed review see Jain et al., 1997): (a) complicated surgical techniques are required; (b) only a limited number of test compounds can be assayed (in the case of the micropocket assay, for example); and (c) simultaneous assessment of both angiogenic and anti-angiogenic compounds in the same assay is not feasible without the addition of exogenous growth factors. Fortunately, the method described here is free from these limitations. Fujita et al. (2002) used this culture method to test angiogenic and anti-angiogenic agents (TNF- $\alpha$, thalidomide). The in vivo mechanism of angiogenesis is very complex, involving not only endothelial cells but also other cellular components such as pericytes, 

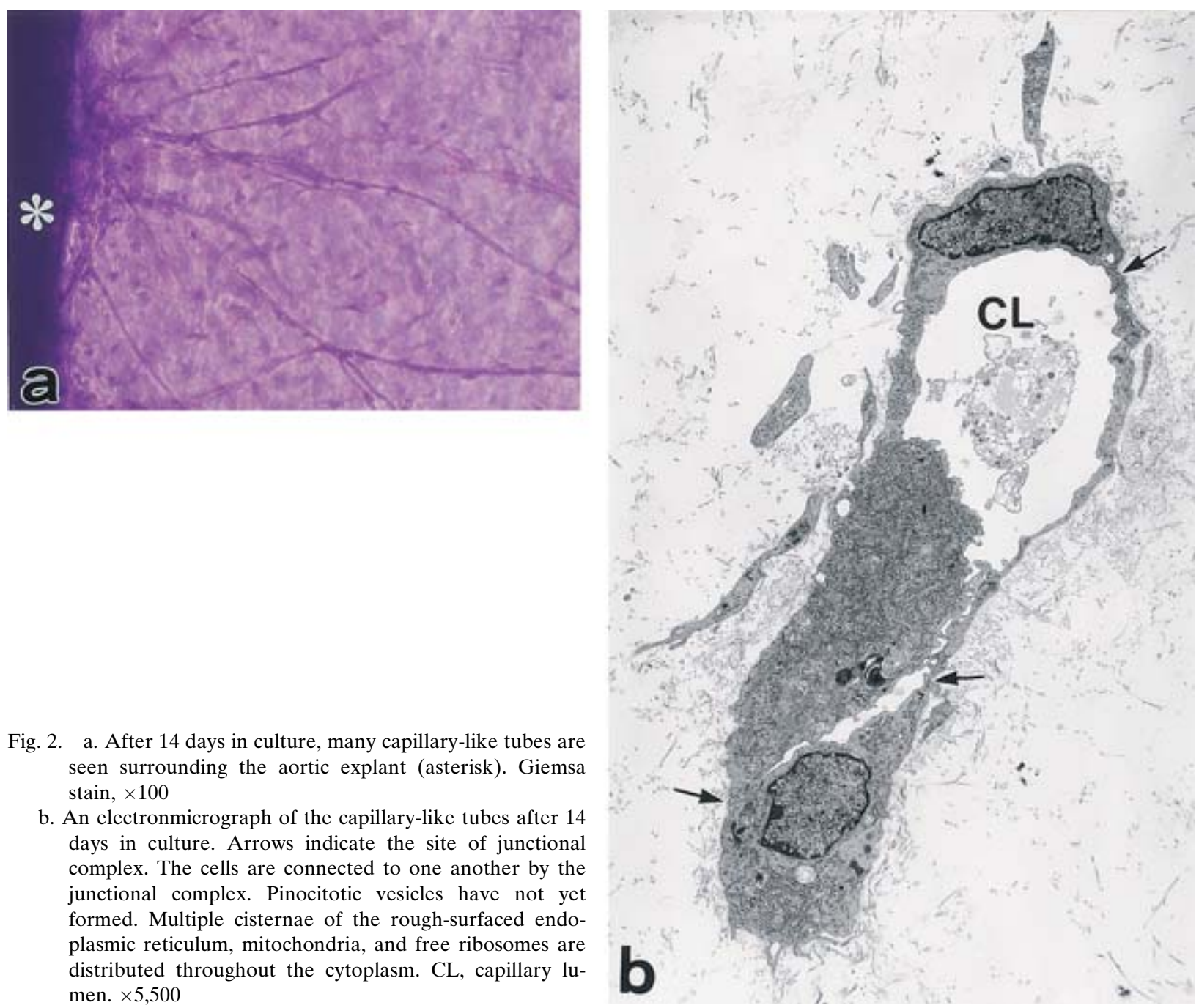

Fig. 2. a. After 14 days in culture, many capillary-like tubes are seen surrounding the aortic explant (asterisk). Giemsa stain, $\times 100$

b. An electronmicrograph of the capillary-like tubes after 14 days in culture. Arrows indicate the site of junctional complex. The cells are connected to one another by the junctional complex. Pinocitotic vesicles have not yet formed. Multiple cisternae of the rough-surfaced endoplasmic reticulum, mitochondria, and free ribosomes are distributed throughout the cytoplasm. CL, capillary lumen. $\times 5,500$

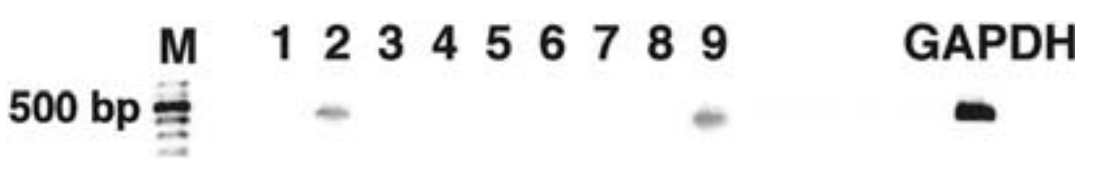

Fig. 3. RT-PCR of FGF cDNAs. Nine FGFs were analyzed. After 14 days in culture, the expressions of FGF-2 (lane 2) and FGF-9 (lane 9) were detectable in the capillary-like tubes and in the cells that had migrated from the aortic explant. Lane $\mathrm{M}$ is a morecular marker.

smooth muscle cells, fibroblasts, and macrophages. Extracellular matrix, angiogenic factors, and adhesive molecules (integrins) also play important roles in angiogenesis. Compared with the techniques using only endothelial cells, the in vitro model for the study of angiogenesis described here permits the observation of angiogenesis within more of an in vivo environment. In the present study, we initially observed fibroblastic cells actively migrating from the aortic explant, and this was followed by 


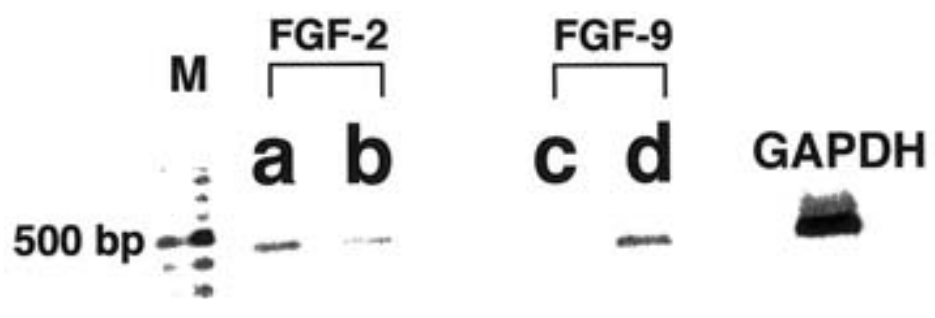

Fig. 4. RT-PCR of FGF-2 and FGF-9 cDNAs.

a. FGF-2, after 5 days in culture. FGF-2 expression was detectable, but capillary-like tube formation was not observed.

b. FGF-2, after 14 days in culture. FGF-2 expression was detectable, and capillary-like tubes were formed.

c. FGF-9, after 5 days in culture. FGF-9 expression was not detectable, and capillary-like tubes were not formed.

d. FGF-9, after 14 days in culture. FGF-9 expression was observed. Lane M is a morecular marker.

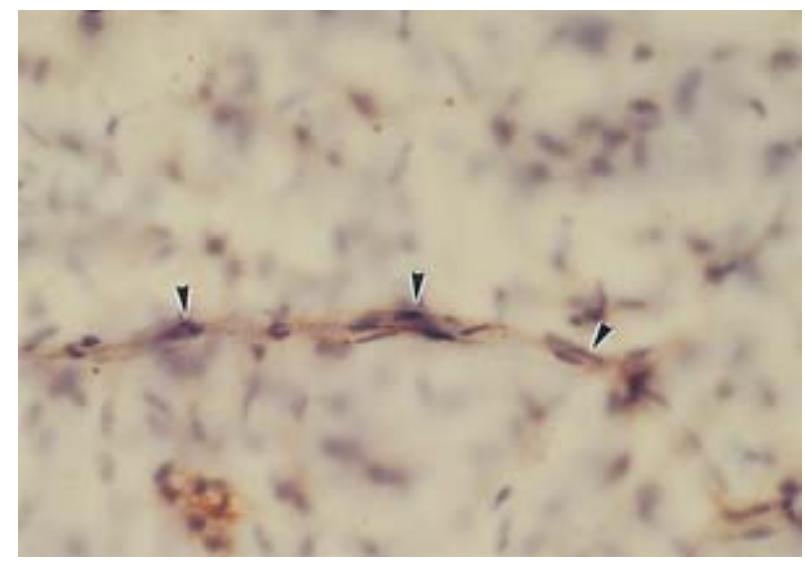

Fig. 5. Immunostaining using anti factor VIII-related antigen antibody. After 14 days in culture, the reddish brown color of the newly formed capillary-like strand indicates positive staining for antibody to factor VIII-related antigen (arrowheads). Nuclei were stained dark blue with hematoxylin. $\times 175$
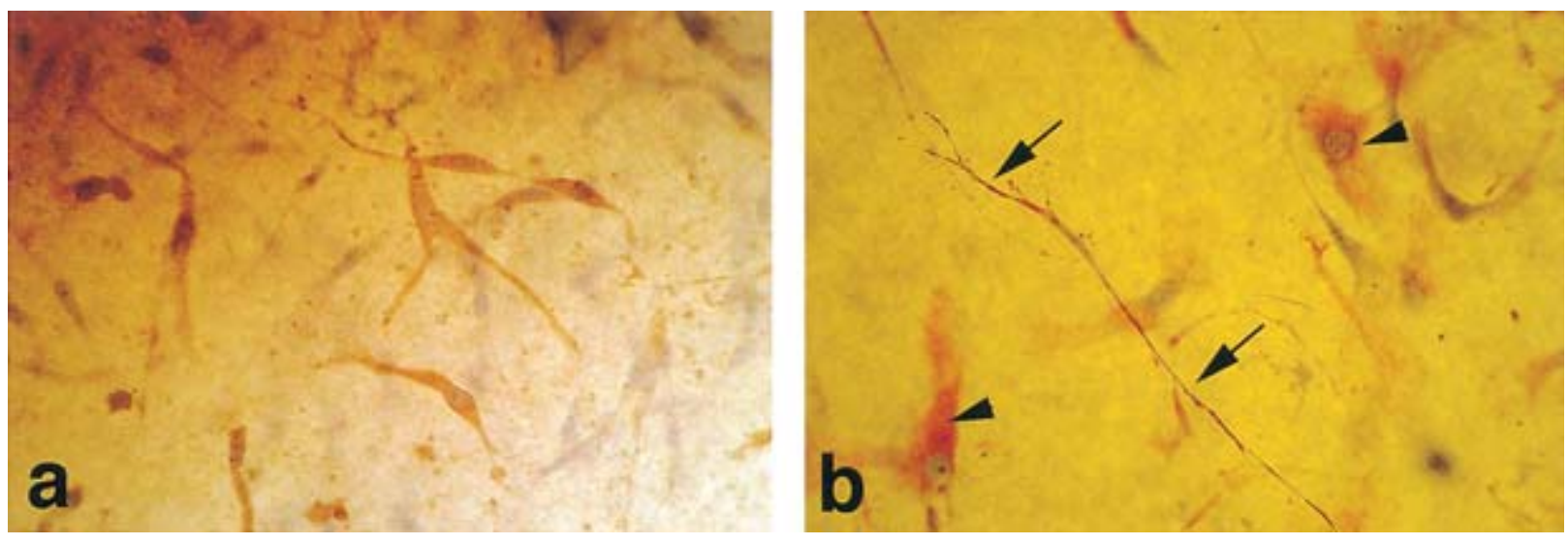

Fig. 6. a. Immunostaining using anti FGF-2 antibody. After 5 days in culture, migrating cells from the aortic explant showed positive reaction. Capillary-like tubes were not formed. The aortic explant located in the upper left corner. $\times 175$

b. Immunostaining using anti FGF-9 antibody. After 14 days in culture, migrating cells from the aortic explant showed a positive reaction. Arrowheads indicate widely spread cells grown on the bottom of the culture dish. Arrows indicate cells with fine processes. $\times 175$ 
the formation of capillary-like tubes. Brown et al. (1996) also observed the formation of capillary-like tubes from a placental blood vessel stump embedded in fibrin gel, but they turned their focus away from this finding in order to investigate the migration of fibroblasts preceding the formation of capillary-like tubes. Deckers et al. (2001) described the use of fetal mouse metatarsals to study the formation of capillary-like tubes. In their experiments, the formation of PECAM-1-positive tubelike structures was observable from day 7 , after a feeder layer of fibroblast-like cells had been formed. To explain the time lag, they speculated that the endothelial cells might have required the feeder layer of fibroblastic cells as a pathway along which to migrate. Our present findings suggest that migration of fibroblastic cells before the formation of capillary-like tubes is quite an important event for angiogenesis. These fibroblastic cells act as a feeder layer and may produce various angiogenic factors.

Angiogenesis will not take place without angiogenic growth factors, including FGF-2 (Montesano et al., 1986), FGF-2 and VEGF (Folkman and Shing, 1992). Angiogenic growth-regulatory molecules are thought to be inducers of mitogenesis in vascular endothelial cells, as the formation of new vessels depends on endothelial proliferation. VEGF is a growth factor that acts specifically on vascular endothelial cells. Gerber et al. (1999) suggested that VEGF is a key regulator of angiogenesis during bone development. In a study using fibrin gel, Brown et al. (1996) found that both VEGF and FGF-2 mRNAs were expressed in the cells migrating from the placental blood vessel stump. In our previous experiment, VEGF promoted cell outgrowth from aortic explant (Akita et al., 1996). According to Cancilla et al. (2001), fibroblast growth factors (FGFs) are a family of at least 21 heparin-binding proteins involved in many biological processes including angiogenesis. FGF-2, a potent angiogenic molecule in vivo and in vitro, stimulates endothelial cell growth (Moscatelli et al., 1986; Presta et al., 1986; Leach et al., 1997), smooth muscle cell growth, wound healing, and tissue repair (Basilico and Moscatelli, 1992; Schwartz and Liaw, 1993). This FGF prototype has pleiotropic effects in different cell and organ systems. Kuzuya et al. (1999) and Satake et al. (1998) reported that FGF-2 plays important roles in angiogenesis. When fetal bovine aortae (BAECs) were embedded in collagen gels, they underwent apoptotic death within 2 days unless the cultures were repeatedly supplied with FGF-2. Supplementation with FGF-2 induced endothelial cell differentiation, resulting in capillarylike tube formation inside collagen gels. Endothe- lial cells derived from BAECs undergo apoptosis in three-dimensional (3-D) type I collagen gels in the absence of FGF-2. In the presence of FGF-2, BAECs survive and form a capillary-like tube structure in 3-D culture. In the study by Brown et al. (1996) using fibrin gel, FGF-1 mRNA was also expressed in the cells migrating from the placental blood vessel stump. In the present study, we could not detect the expression of FGF-1 mRNA. FGF-1, like its relative FGF-2, stimulates angiogenesis both in vitro and in vivo (Maciag, 1990). However, FGF1 is not significantly expressed in endothelial cells, suggesting a paracrine mechanism of action. Smooth muscle cells express FGF-1, and this expression may be involved in the induction of neovascularization in atherosclerotic lesions (Maciag, 1990; Nabel et al., 1993). In the RT-PCR and immunohistochemical investigations of our present study, the expression of FGF-9 was dominant within the FGF family. FGF-9, glia-activating factor originally cloned from human glioma cells, stimulates the cell growth of fibroblasts and glial cells and is expressed in the brain and kidney of adult rat (Naruo et al., 1993; Miyamoto et al., 1993). The biological roles of FGF-9 are not well known. Pilcher et al. (1997) and Miyagi et al. (1998) reported that FGF-9 relates to the expression of matrix metalloproteinases (MMPs) and their inhibitors through the FGF cell-surface receptor (FGFR). Haas et al. (1998) hypothesized that MMPs play a key role in the processes of endothelial cell migration and matrix remodeling during angiogenesis. They reported that three-dimensional type I collagen gels induced coordinate expression of matrix metalloproteinases MMP-2 and MT1-MMP (membrane type I-MMP) in microvascular endothelial cells. Further studies of MMP and FGFR are needed to clarify the angiogenic roles of FGF-9. FGFs mediate essential cellular functions by activating one of four alternatively spliced FGFRs (Chellaiah et al., 1999). Since FGF-9 and other members of the FGF family can bind to the same receptors as FGF-2, they may also prove to be angiogenic, if expressed at appropriate levels in specific sites. In this study, we propose that FGF-9 works alongside FGF-2 in inducing angiogenesis in vitro.

\section{Acknowledgments}

We wish to express out gratitude for the intellectual guidance of Prof. Dr. Katsuji Kaneko from the Department of Anatomy at the Saitama Medical School. This work was partly supported by a grant to the Saitama Medical School Research Center for Genomic Medicine. 


\section{References}

1) Adams RH, Wilkinson GA, Weiss C, Diella F, Gale NW, Deutsch U, Risau W and Klein R. Roles of ephrinB ligands and EphB receptors in cardiovascular development demarcation of arterial/venous domains, vascular morphogenesis, and sprouting angiogenesis. Genes Dev 1999; 13:295-306.

2) Akita M, Murata E, Kaneko K, Ghaida J and Merker HJ. Cell shape and arrangement of cultures aortic smooth muscle cells grown on collagen gels. Cell Tissue Res 1993; 274:91-95.

3) Akita M, Murata E, Merker HJ and Kaneko K. Formation of new capillary-like tubes in a three-dimensional in vitro model (aorta/collagen gel). Ann Anat 1997a; 179:127-136.

4) Akita M, Murata E, Merker HJ and Kaneko K. Morphology of capillary-like structures in a three-dimensional aorta/collagen gel culture. Ann Anat 1997b; 179:137147.

5) Akita M, Murata, Fujita K, Kaneko $K$ and Merker HJ. Observation of capillary-like tubes newly formed from the aorta specimen in collagen gel and the effects of growth factors. Acta Anat Nippon 1996; 71:426.

6) Basilico $\mathrm{C}$ and Moscatelli $\mathrm{D}$. The FGF family of growth factors and oncogenes. Adv Cancer Res 1992; 59:115-165.

7) Bikfalvi A, Klein S, Pintucci G and Rifkin DB. Biological Roles of Fibroblast Growth Factor-2. Endocrine Reviews 1997; 18:26-45.

8) Brown KJ, Maynes SF, Bezos A, Maguire DJ, Ford MD and Parish CR. A novel in vitro assay for human angiogenesis. Lab Invest 1996; 75:539-555.

9) Cancilla B, Davies A, Cauchi JA, Risbridger GP and Bertram JF. Fibroblast growth factor receptors and their ligands in the adult rat kidney. Kidney Int 2001; 60:147155.

10) Chellaiah A, Yuan W, Chellaiah M and Ornitz DM. Mapping ligand binding domains in chimeric fibroblast growth factor receptor molecules. Multiple regions determine ligand binding specificity. J Biol Chem 1999; 274:3478534794.

11) Deckers M, van der Pluijm G, Dooijewaard S, Kroon M, van Hinsbergh V, Papapoulos S and Lowik C. Effect of angiogenic and antiangiogenic compounds on the outgrowth of capillary structures from fetal mouse bone explants. Lab Invest 2001; 81:5-15.

12) Erlebacher A, Filvaroff E, Gitelman SE and Derynck R. Toward a molecular understanding of skeletal development. Cell 1995; 80:371-378.

13) Folkman J and Shing Y. Angiogenesis. J Biol Chem 1992; 267:10931-10934.

14) Folkman J and Haudenschild C. Angiogenesis in vitro. Nature (Lond.) 1980; 288:551-556.

15) Fournier GA, Lutty GA, Watt S, Fenselau A and Patz A. A corneal micropocket assay for angiogenesis in the rat eye. Invest Ophthalmol Vis Sci 1981; 21:351-354.

16) Fujita K, Asami Y, Murata E, Akita M and Kaneko K. Effects of thalidomide, cytochrome P-450 and TNF-alpha on angiogenesis in a three-dimensional collagen gel-culture. Okajimas Folia Anat Jpn 2002; 79:101-106.

17) Gerber HP, Vu TH, Ryan A, Kowalski J, Werb $Z$ and Ferrara N. VEGF couples hypertrophic cartilage remodeling, ossification and angiogenesis during endochondral bone formation. Nature Med 1999; 5:623-628.

18) Haas TL, Davis SJ and Madri JA. Three-dimensional type I collagen lattices induce coordinate expression of matrix metalloproteinases MT1-MMP and MMP-2 in microvascular endothelial cells. J Biol Chem 1998; 273:3604-3610.
19) Jain RK, Schlenger K and Yuan F. Quantitative angiogenesis assays: Progress and problems. Nat Med 1997; 3:1203-1208.

20) Jakob WG, Jentzsch KD, Mauersberge TB and Heder G. The chick embryo choriallantoic membrane as a bioassay for angiogenesis factors: Reactions induced by carrier materials. Exp Pathol (Jena) 1978; 15:241-249.

21) Kenyon BM, Voest EE, Chen CC, Flynn E, Folkman J and D'Amato RJ. A model of angiogenesis in the mouse cornea. Invest Ophthalmol Vis Sci 1996; 37:1625-1632.

22) Kuzuya M, Satake S, Ramos MA, Kanda S, Koike T, Yoshino K, Ikeda S and Iguchi A. Induction of apoptotic cell death in vascular endothelial cells cultured in threedimensional collagen lattice. Exp Cell Res 1999; 248:498508.

23) Leach RM Jr, Sokol C and McMurtry JP. Immunolocalization of basic fibroblast growth factor in porcine epiphyseal growth plate. Domest Anim Endocrinol 1997; 14:129-132.

24) Maciag T. Molecular and cellular mechanisms of angiogenesis. Important Adv Oncol 1990; 85-98.

25) Miyagi $N$, Kato $S$, Terasaki $M$, Shigemori $M$ and Morimatsu M. Fibroblast growth factor-2 and 9 regulate proliferation and production of matrix metalloproteinases in human gliomas. Int J Oncol 1998; 12:1085-90.

26) Miyamoto $M$, Naruo $K$, Seko $C$, Matsumoto $S$, Kondo $T$ and Kurokawa T. Molecular cloning of a novel cytokine cDNA encoding the ninth member of the fibroblast growth factor family, which has a unique secretion property. Mol Cell Biol 1993; 13:4251-4259.

27) Montesano R, Orci L and Vassalli P. In vitro rapid organization of endothelial cells into capillary-like networks is promoted by collagen matrices. J Cell Biol 1983; 97:16481652.

28) Montesano R, Vassalli JD, Baird A, Guillemin R and Orci L. Basic fibroblast growth factor induces angiogenesis in vitro. Proc Natl Acad Sci USA 1986; 83:7297-7310.

29) Montesano R, Mouron P and Orci L. Vascular outgrowths from tissue explants embedded in fibrin or collagen gels: A simple in vitro model of angiogenesis. Cell Biol Int Rep 1985; 9:869-875.

30) Mori M, Sadahira Y, Kawasaki S, Hayashi Y, Notohara K and Awai M. Capillary growth from reversed rat aortic segments cultured in collagen gel. Acta Pathol Jpn 1988; 38:1503-1512.

31) Moscatelli D, Presta M, Rifkin DB. Purification of a factor from human placenta that stimulates capillary endothelial cell protease production, DNA synthesis, and migration. Proc Natl Acad Sci USA. 1986; 83:2091-2095.

32) Nabel EG, Yang ZY, Plautz G, Forough R, Zhan X, Haudenschild CC, Maciag T and Nabel GJ. Recombinant fibroblast growth factor-1 promotes intimal hyperplasia and angiogenesis in arteries in vivo. Nature 1993; 362:844846.

33) Naruo K, Seko C, Kuroshima K, Matsutani E, Sasada R, Kondo $T$ and Kurokawa $T$. Novel secretory heparinbinding factors from human glioma cells (glia-activating factors) involved in glial cell growth. Purification and biological properties. J Biol Chem 1993; 268:2857-2864.

34) Nicosia RF and Ottinetti A. Modulation of microvascular growth and morphogenesis by reconstituted basement membrane gel in three-dimensional cultures of rat aorta: a comparative study of angiogenesis in matrigel, collagen, fibrin, and plasma clot. In Vitro Cell Dev Biol 1990a; 26:119-128.

35) Nicosia RF and Ottinetti A. Growth of microvessels in serum-free matrix culture of rat aorta: A quantitative assay of angiogenesis in vitro. Lab Invest 1990b; 63:115-122. 
36) Nissen NN, Polverini PJ, Koch AE, Volin MV, Gamelli RL and DiPietro LA. Vascular endothelial growth factor mediates angiogenic activity during the proliferative phase of wound healing. Am J Pathol 1998; 152:14451452.

37) Ozawa K, Seo M and Imamura T. A quantitative method for evaluation of FGF family and FGF receptor family gene expression by RT-PCR. Brain Res Brain Res Protoc 1997; 1:211-216.

38) Pilcher BK, Gaither-Ganim J, Parks WC and Welgus HG. Cell type-specific inhibition of keratinocyte collagenase-1 expression by basic fibroblast growth factor and keratinocyte growth factor. A common receptor pathway. J Biol Chem 1997; 272:18147-18154.

39) Presta M, Moscatelli D, Joseph-Silverstein J and Rifkin
DB. Purification from a human hepatoma cell line of a basic fibroblast growth factor-like molecule that stimulates capillary endothelial cell plasminogen activator production, DNA synthesis, and migration. Mol Cell Biol 1986; 6:40604066.

40) Satake S, Kuzuya M, Ramos MA, Kanda S and Iguchi A. Angiogenic stimuli are essential for survival of vascular endothelial cells in three-dimensional collagen lattice. Biochem Biophys Res Commun 1998; 244:642-646.

41) Schwartz SM and Liaw L. Growth control and morphogenesis in the development and pathology of arteries. J Cardiovasc Pharmacol 1993; 21 [Suppl]: S31-S49.

42) Tamura H and Greenwald GS. Angiogenesis and its hormonal control in the corpeus luteum of the pregnant rat. Biol Reprod 1987; 36:1149-1154. 